\title{
Development of a new test rig for the analysis of hydrodynamic bearings for rotors of microGT
}

\author{
Carlo Alberto Niccolini Marmont Du Haut Champ ${ }^{1,{ }^{*}}$, Fabrizio Stefani ${ }^{1}$, and Paolo \\ Silvestri ${ }^{1}$ \\ ${ }^{1}$ University of Genoa, DIME, 16145 Genoa, Italy
}

\begin{abstract}
The aim of the present work is to design a test rig suited to investigate the dynamic interaction between rotor and hydrodynamic journal bearings in micro gas turbines (microGT), i.e. with reference to small bearings (diameter in the order of ten millimeters). Particularly, the device is capable of measuring the journal location. Therefore, the journal motion due to rotor vibrations can be displayed, in order to assess performance as well as stiffness and damping of the bearings. The new test rig is based on Bently Nevada Rotor Kit (RK), but substantial modifications are carried out. Indeed, the relative radial clearance of the original RK bearings is about $2 / 100$, while it is in the order of $1 / 1000$ in industrial bearings. Therefore, the same RK bearings are employed in the new test rig, but a new shaft has been designed in order to reduce the original clearance. The new shaft enables us to study the bearing behaviour for different clearances, as it is equipped with interchangeable journals. The experimental data yielded by the new test rig are compared with numerical results. These are obtained by means of a suitable finite element (FEM) code developed by our research group. It allows the Thermo ElastoHydroDynamic (TEHD) analysis of the bearing in static and dynamic conditions. In the present paper, bearing static performances are analysed in order to assess the reliability of the journal location predictions by comparing numerical and experimental results. Such comparisons are presented for both large and small clearance bearings of original and modified RK, respectively. Good agreement is found only for the modified RK equipped with small clearance bearings (relative radial clearance equal to $8 / 1000$ ). Nevertheless, rotor alignment is quite difficult with small clearance bearings and a completely new test rig is designed for future experiments.
\end{abstract}

\section{Introduction}

Gas turbines and particularly microGT may be equipped with fluid film bearings. They work by means of a thin self-pressurized lubricant film formed between the two opposing bearing surfaces in relative motion. In microGT applications, assuming the usual relative radial clearance (1/1000), since bearing journal diameters are as large as $10-20 \mathrm{~mm}$, bearing

\footnotetext{
* Corresponding author: carloalberto.niccolinimarmontduhautchamp@edu.unige.it
} 
fluid film thickness is in the order of 10 microns. Therefore, high-quality standards are required for this kind of bearings, which must be manufactured with high precision.

The dynamic behaviour of small hydrodynamic journal bearings has already been studied in several works by using numerical methods and RK-type test rigs. In example, Tůma and Biloš [1], who have studied the stability of the rotor vibration in a journal bearing by means of full spectrum analysis and Bently Nevada RK 4 Rotor Kit device, have concluded that the journal motion in bearings is governed by two equations of motion, referred to as linear and non-linear models. Meruane and Pascual [2] have found that nonlinear dynamic coefficients affect stiffness and damping. They have employed a CFD model in ADINA and Bently Nevada Rotor Kit 2000. Tủma et al. [3] have carried out experimental and theoretical analysis to determine the influence of external excitation on rotor behaviour. According to their results, kinematic excitation can affect amplitudes of vibration but not the stability limit. They have taken advantage of a lumped parameter model, Bently Nevada RK 4 and a suitable test stand (bearing diameter $30 \mathrm{~mm}$ ) for the rotor active control investigation.

All of these works employ experimental data obtained by means of large clearance journal bearings, when compared to industrial ones, which relative radial clearance is in the order of 1/1000. Indeed, the relative radial clearance of Bently Nevada RK 4 bearings is $1.7 / 100$ at ambient temperature, as reported below, while for Bently Nevada Rotor Kit 2000 a relative radial clearance of $1.3 / 100$ is reported [2]. In addition, due to differential thermal dilatation the (hot) relative clearance becomes larger during operation.

This research project is aimed to develop a test rig and simulation methods suited to study the performance of small fluid film bearings for rotors, i.e. for microGT applications, with particular reference to their vibrational behaviour. In such perspective, prediction and measurement of journal locations are particularly important. In addition, the test rig bearings must have reasonable relative clearance. Indeed, its value should be typical of real bearings and, simultaneously, it should still allow the assembly of the test rig and the alignment of the two supports of the shaft. Therefore, in the present paper, in order to determine the design and a basic set-up of the test rig, the influence of bearing clearance in the assessment of the static journal position in hydrodynamic plain bearings is studied by comparing experimental and numerical results.

Numerical simulations have been performed by using a previously validated ([4-5]) code for journal bearing analysis. Since the simulation model takes advantage of the classical Reynolds hypothesis that assumes a thin film, the bearing clearance must be sufficiently small.

\section{Experimental devices}

Rotordynamic analyses can be performed on rotor models, configured to reproduce particular working conditions of rotating machines. Initial experiments have been performed on the original RK. Later, a modified version of the RK has been designed for further measurements. For future tests, a brand-new design of the RK is briefly explained.

The first experimental device used for investigations is the RK4 Rotor Kit designed and produced by Bently Nevada [6]. Such original $R K$ is a modular rotating machine, which can be assembled and operated in different configurations. In the original arrangement adopted in the experiments, the rotor is supported by a fluid film bearing and a selflubricated bush located at the opposite end of the shaft. It is equipped with an electric motor, which allows adjustment of angular speed in modulus and direction in the range 250-10,000 rpm. The frame has a V-shaped design and it houses motor, bearings and shaft. The fluid film bearing works in hydrodynamic lubrication regime under nominal supply pressure $(7 \mathrm{kPa})$ and, in order to show possible suppression of oil whirl, it can add 
hydrostatic lift when is fed at higher pressure (up to $240 \mathrm{kPa}$ ). The bearing assembly includes holes that support proximity probes. These magnetic sensors are capable of detecting in terms of voltage the journal displacements in two directions ( $X$ and $Y$ ) normal to the rotor axis. The acquisition hardware and software provided by Siemens are LMS Scadas III and LMS Test Lab, respectively.

Bently Nevada original fluid film bearing has high relative radial clearance, i.e. one order of magnitude more than in industrial and automotive applications. Therefore, in order to increase the correlation between experiments and real-world applications, a new shaft with increased and variable journal diameter is designed so that the fluid film bearing clearance can be reduced without changing the bush. The rotor designed for such modified $R K$ is shown in Fig. 1. It is equipped with two interchangeable journals, so that bearing clearance can become a parameter of the experiments. The journal equipped with proximity probes can be easily assembled by means of a splined connection.

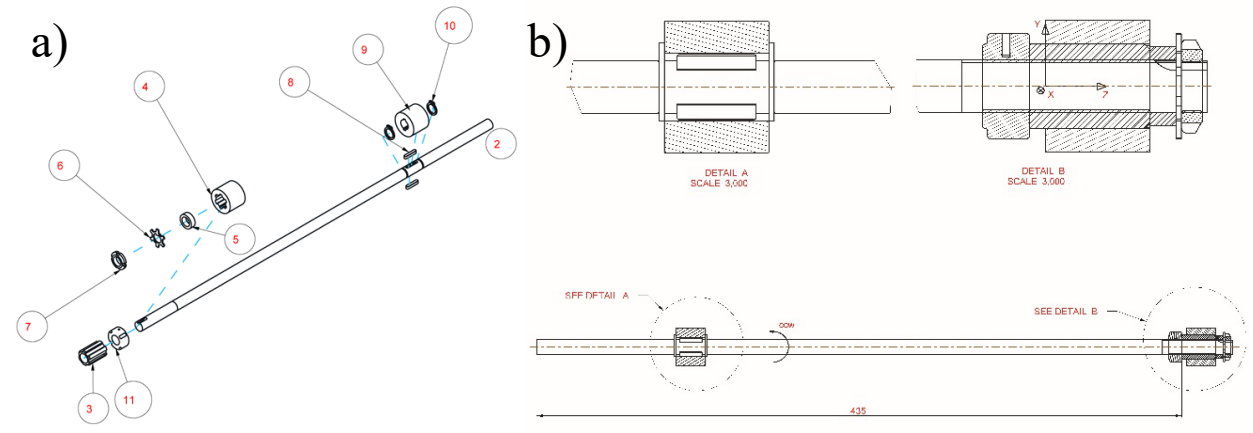

Fig. 1. Rotor designed for the modified RK: a) exploded view, b) section. The following components are shown: 2-shaft; 3-splined connection; 4-splined hub (journal 1); 5-spacer; 6-safety washer; 7threaded locking nut; 8-key; 9-hub with keyways (journal 2); 10-retaining ring; 11-lock nut with locking screw.
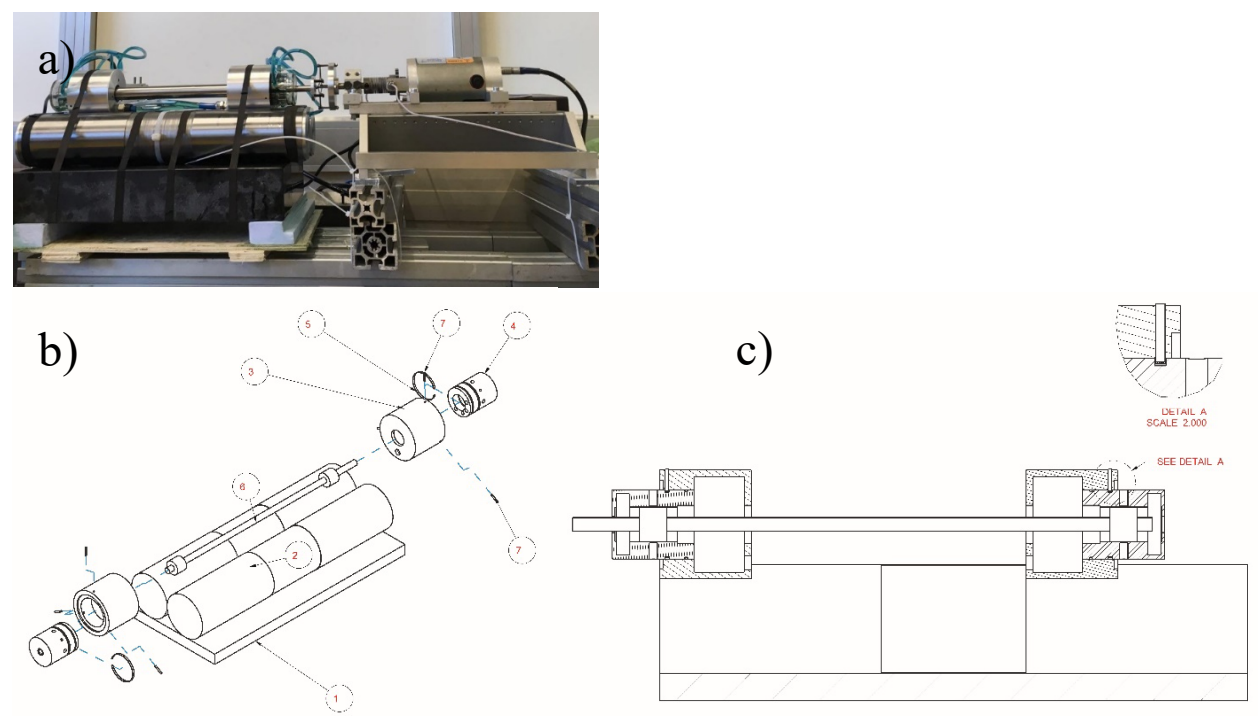

Fig. 2. Prototype of the new RK: a) picture of front view; b) exploded view; c) section. The following components are shown: 1-block; 2-ground round bar; 3-external bush; 4-bearing; 5-spacer; 6-shaft; 7set screw. 
Experiments are carried out in two configurations. The former (configuration 1), inherited from the original RK, arranges at opposite ends of the shaft the fluid film bearing and a self-lubricated bush. In configuration 2 it is replaced by a second identical fluid film bearing in order to avoid possible lift-off of the journal in the self-lubricated bearing [7].

After all of the measurements have been carried out, the design of a new test rig has been required. Indeed, in the modified RK the difficulty in the alignment of the two shaft supports due to their small clearance limits the repeatability of the measurements.

In order to improve the alignment procedure, the new $R K$, shown in Fig. 2, has a frame made up by two cylindrical bars put in contact along their generatrices. The two bearing bushes are placed tangent to the bars. Both bush external surfaces and round bars are manufactured by precision grinding in order to ensure the required assembly tolerance.

\section{Numerical models}

The experimental data are compared in the successive paragraphs with numerical results obtained by means of the two ThermoHydroDynamic (THD) analysis methods described in [8]. Such models allow the simulation of the fluid flow in the thin oil film as well as of heat generation and exchange in the lubricant. In addition, the most advanced one includes the simulation of heat conduction in the bush and journal. Solution algorithm and theoretical aspects are explained in $[4,5]$. The models, which require the solution of integrodifferential problems, use the finite element method (FEM) for the discretization. Isoparametric 4-node rectangular elements are used.

Both of them take advantage of mass conserving hydrodynamic simulation based on the JFO theory [9-10], which is valid for moderately and highly loaded bearings and assumes a cavitated film region with infinite streamers and variable density $\rho$. According to JFO theory, thin film mechanics equation for journal bearings is:

$$
\frac{\rho_{L}}{R^{2}} \frac{\partial}{\partial \vartheta}\left(\frac{H^{3}}{12 \mu_{L}} \frac{\partial p}{\partial \vartheta}\right)+\rho_{L} \frac{\partial}{\partial z}\left(\frac{H^{3}}{12 \mu_{L}} \frac{\partial p}{\partial z}\right)-\frac{\omega}{2} \frac{\partial}{\partial \vartheta}(\rho H)-\frac{\partial}{\partial t}(\rho H)=0
$$

where $p$ is the hydrodynamic pressure, $R$ the journal radius, $\rho$ the fluid film density, $\rho_{L}$ the liquid phase density, $H$ the film thickness, $\vartheta$ the circumferential coordinate, $z$ the axial coordinate, $t$ the time, $\mu_{L}$ the liquid dynamic viscosity.

Equation (1) is solved in weak form [5]. The thermal models rely on the cross-film averaged energy equation:

$$
\frac{\partial}{R^{2} \partial \vartheta}\left(k H \frac{\partial T_{m}}{\partial \vartheta}\right)+\frac{\partial}{\partial z}\left(k H \frac{\partial T_{m}}{\partial z}\right)-\rho c H\left(u_{m} \frac{\partial T_{m}}{R \partial \vartheta}+w_{m} \frac{\partial T_{m}}{\partial z}\right)-\rho c H \frac{\partial T_{m}}{\partial t}+H \Phi_{m}-q_{0}-q_{1}=0
$$

where $u$ and $w$ are the circumferential and axial fluid velocities, respectively, $k$ the conductivity of the film, $c$ the specific heat, $T$ the film temperature, $\Phi$ the power dissipation density function and the subscript $m$ denotes a variable averaged in the cross-film direction.

In addition, $q_{0}$ and $q_{1}$ are the heat fluxes to bearing and journal surfaces, respectively. If they are both equal to zero, in the result paragraph the thermal model is referred to as " $2 \mathrm{D}$ adiabatic" [11], although heat exchange is allowed in the feed grooves [4]. Differently, in the "2D correlation" model, $q_{0}$ and $q_{1}$ are computed by using Luke formula [12] and the heat exchange is roughly taken into account.

\section{Results}

Static characteristics have been computed by means of the two above-explained simulation models for both original and modified RK. The same bearing bushes are employed in the two test rigs, while journal diameters are different, so that radial relative clearances are 
$1.7 / 100$ and $8 / 1000$, respectively. Lubricant supply is carried out by means of four holes in the bearing axial midplane oriented at 45 degrees with reference to the vertical direction. Bearing data required by both lubrication analysis methods are given in Table 1. Hot clearances $c_{h}$ are used as input data for THD calculations. Here the temperature-viscosity dependence is described by means of three parameters (reference oil viscosity $\mu_{L 0}$ at temperature $T_{0}$ and coefficient $\beta$ ) according to the exponential law described in $[4,5]$. The oil film in half bearing is discretized by means of $80 \times 8$ elements in circumferential and axial directions, respectively.

Table 1. Lubrication analysis data

\begin{tabular}{|c|c|c|c|c|c|c|c|c|c|c|c|}
\hline & $\begin{array}{c}\text { Parameter } \\
\text { [unit }]\end{array}$ & Symbol & Value & & $\begin{array}{c}\text { Parameter } \\
\text { [unit] }\end{array}$ & Symbol & Value & & $\begin{array}{c}\text { Parameter } \\
\text { [unit] }\end{array}$ & Symbol & Value \\
\hline \multirow{11}{*}{ Geometry } & $\begin{array}{c}\text { Bearing } \\
\text { length }[\mathrm{mm}]\end{array}$ & $L$ & 20 & \multirow{5}{*}{$\begin{array}{c}\text { Lubricant } \\
\text { (CHEVRON } \\
\text { GST Oil 32) } \\
\text { properties }\end{array}$} & $\begin{array}{c}\text { Viscosity lat } \\
T_{0}=40^{\circ} \mathrm{C} \text { ) } \\
{[\text { Pa s }]}\end{array}$ & $\mu_{r, 0}$ & 0.0251 & \multirow{8}{*}{$\begin{array}{l}\text { Working } \\
\text { conditions }\end{array}$} & \multirow{3}{*}{$\begin{array}{c}\text { Bearing load } \\
\text { (half shaft } \\
\text { weight) for } \\
\text { original RK } \\
{[\mathrm{N}]}\end{array}$} & \multirow{3}{*}{$W_{g}$} & \multirow{3}{*}{$5.6 / 2$} \\
\hline & $\begin{array}{c}\text { Journal } \\
\text { diameter } \\
{[\mathrm{mm}]}\end{array}$ & $D$ & $\begin{array}{l}25.245- \\
25.254\end{array}$ & & $\begin{array}{c}\text { Viscosity } \\
\text { temperature } \\
\text { coefficient } \\
{\left[1 /{ }^{\circ} \mathrm{C}\right]}\end{array}$ & $B$ & 0.0317 & & & & \\
\hline & \begin{tabular}{|c|} 
External \\
diameter of \\
bush $[\mathrm{mm}]$
\end{tabular} & $D_{0}$ & 27 & & $\begin{array}{c}\text { Mass density } \\
{\left[\mathrm{kg} / \mathrm{m}^{3}\right]}\end{array}$ & $\rho_{L}$ & 870 & & & & \\
\hline & $\begin{array}{c}\text { Inner } \\
\text { diameter of } \\
\text { bush [mm] }\end{array}$ & $D_{i}$ & $25.0-25.42$ & & $\begin{array}{c}\text { Specific heat } \\
{\left[\mathrm{J} / \mathrm{Kg}{ }^{\circ} \mathrm{C}\right]}\end{array}$ & $c_{L}$ & 2000 & & $\begin{array}{l}\text { Bearing load } \\
\text { (half shaf } \\
\text { weight) for } \\
\text { modi lied RK } \\
{[\mathrm{N}]}\end{array}$ & $W_{g}$ & $4.28 / 2$ \\
\hline & $\begin{array}{c}\text { Radial } \\
\text { clearance } \\
\text { (original } \\
\text { RK) } \\
\text { [micron] }\end{array}$ & $c$ & 210 & & $\begin{array}{c}\text { Thermal } \\
\text { conductivity } \\
\text { [Wm } / \mathrm{K}]\end{array}$ & $k_{L}$ & 0.14 & & $\begin{array}{c}\text { Environment } \\
\text { al } \\
\text { temperature } \\
{\left[{ }^{\circ} \mathrm{C}\right]}\end{array}$ & $T_{a}$ & 20 \\
\hline & $\begin{array}{c}\text { Hot radial } \\
\text { clearance } \\
\text { (original } \\
\text { RK) } \\
\text { [micron] }\end{array}$ & $c_{h}$ & 260 & \multirow{2}{*}{$\begin{array}{c}\text { Supply } \\
\text { conditions }\end{array}$} & $\begin{array}{c}\text { Feed } \\
\text { tempcrature } \\
{\left[{ }^{\circ} \mathrm{C}\right]}\end{array}$ & $T_{s}$ & 51 & & $\begin{array}{c}\text { Rotation } \\
\text { specd range } \\
\text { [rpm] }\end{array}$ & $\omega$ & $250-3000$ \\
\hline & $\begin{array}{l}\text { Relative } \\
\text { radial } \\
\text { clearance } \\
\text { (original } \\
\text { RK) }\end{array}$ & $c / R$ & $1.68 / 100$ & & $\begin{array}{c}\text { Feed } \\
\text { pressure } \\
{[\mathrm{kPd}]}\end{array}$ & $p_{s}$ & 6.9 & & $\begin{array}{c}\text { Averaged } \\
\text { bush } \\
\text { Lemperature } \\
{\left[{ }^{\circ} \mathrm{C}\right]}\end{array}$ & $T_{B}$ & 51 \\
\hline & $\begin{array}{c}\text { Radial } \\
\text { clearance } \\
\text { (modilied } \\
\text { RK) } \\
\text { [micron] }\end{array}$ & $c$ & 90 & & & & & & $\begin{array}{c}\text { Averaged } \\
\text { journal } \\
\text { temperature } \\
{\left[{ }^{\circ} \mathrm{C}\right]}\end{array}$ & $T_{.4}$ & 40 \\
\hline & $\begin{array}{c}\text { Hot radial } \\
\text { clearance } \\
\text { (modified } \\
\text { RK) } \\
\text { |micron| } \\
\end{array}$ & $c_{i n}$ & 108 & & & & & & & & \\
\hline & $\begin{array}{c}\text { Relative } \\
\text { (hot) radial } \\
\text { clearance } \\
\text { (modified } \\
\text { RK) }\end{array}$ & $c_{h} / R$ & $8 / 1000$ & & & & & & & & \\
\hline & $\begin{array}{c}\text { Diameter of } \\
\text { feed holes } \\
{[\mathrm{mm}]}\end{array}$ & $d_{g}$ & 3.3 & & & & & & & & \\
\hline
\end{tabular}

Experimental and numerical journal center locations (components $X, Y$ ) are shown in Fig. 3, 4 and 5 for the original RK as well as configuration 1 and 2 of the modified RK, respectively. Journal locations are plotted at different shaft rotation speeds $(250,500,1000$, $2000,3000 \mathrm{rpm}$ ) in clockwise (cw) and counter-clockwise (ccw) directions. Let $\varepsilon$ be the operational relative eccentricity equal to $e / c_{h}$, where $e=\left(X^{2}+Y^{2}\right)^{0.5}$. Black and red circles identify the loci of points located at $\varepsilon$ equal to 1 and 0.5 , respectively. Experimental "static" journal points are obtained by averaging the measured locations during several 
shaft rotations. The agreement between experimental and numerical results, based on thin film assumption, is better in modified RK results, due to the clearance reduction. In configuration 1 of modified RK the above-cited lift-off of the journal in the self-lubricated bearing may be influential and, together with misalignment, can explain the occurrence of positive $Y$ components of journal location.

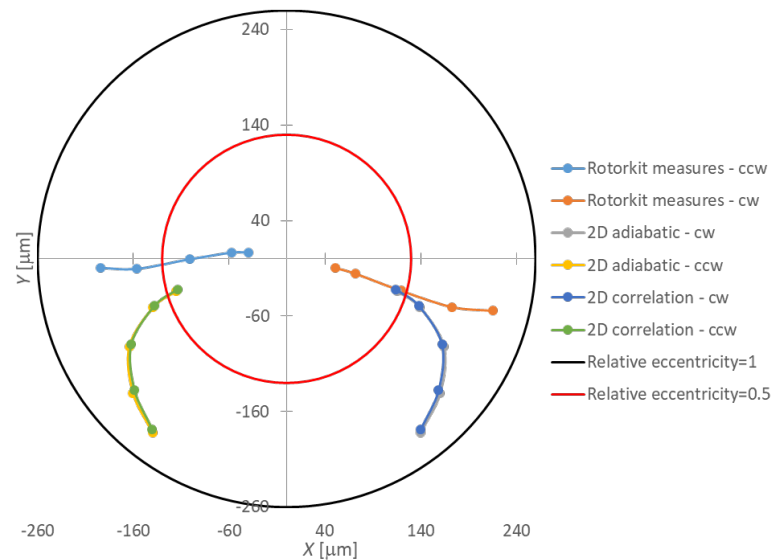

Fig. 3. Journal center locations for the original RK

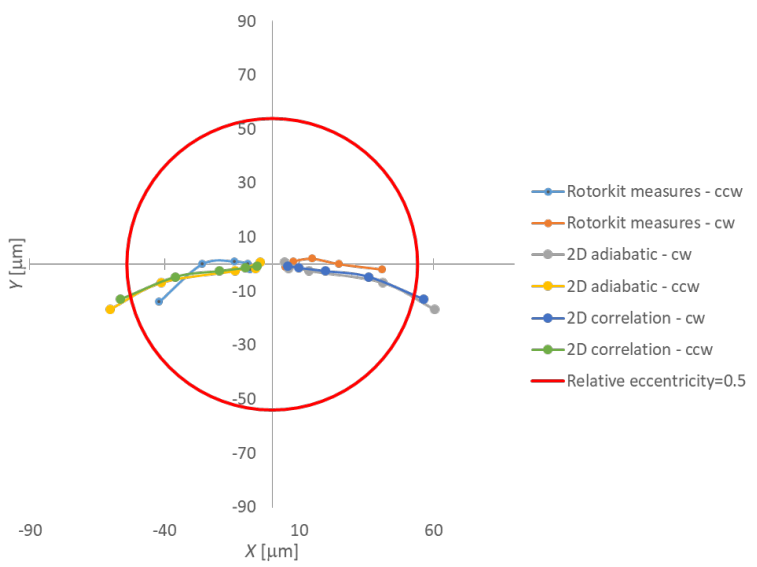

Fig. 4. Journal center locations for the modified RK in configuration 1

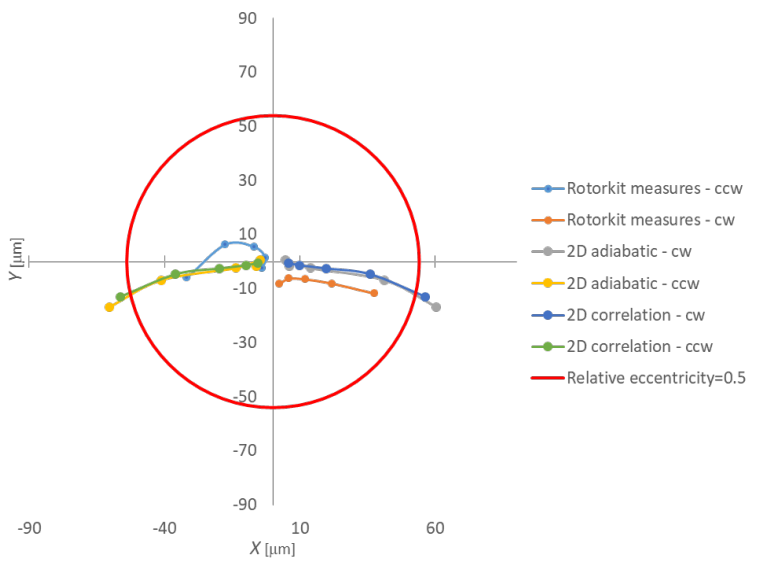

Fig. 5. Journal center locations for the modified RK in configuration 2 
Asymmetry between clockwise and corresponding counter-clockwise experimental locations is mainly due to misalignments. For configuration 2 due to oil whirl instability ccw locations are not significant as well as positive Y components of journal location.

Signal processing has shown that the asymmetry between experimental $\mathrm{cw}$ and $\mathrm{ccw}$ journal positions shown in Fig. 5 is due to whirl phenomenon. Indeed, in the cascade plot recorded at ccw shaft speed (Fig. 6) a line relevant to order 1/2x appears. On the contrary, no corresponding subsynchronous vibration is visible in the cascade plot relevant to $\mathrm{cw}$ speed results (Fig. 7).

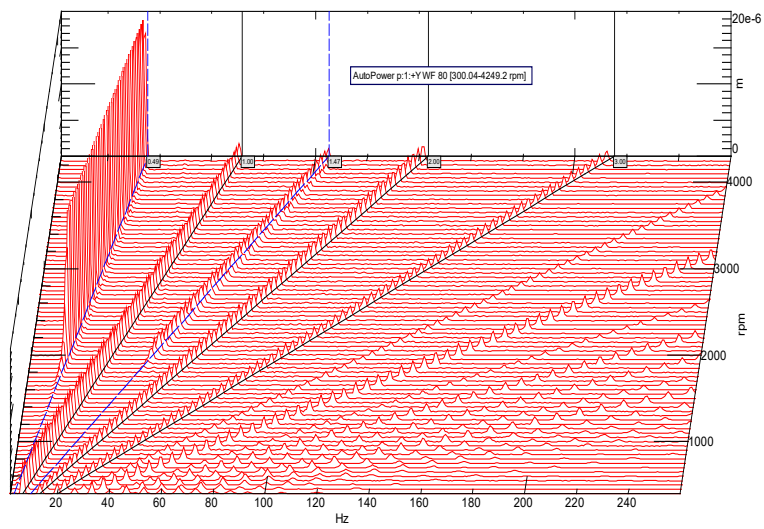

Fig. 6. Cascade plot for modified RK in configuration 2, ccw rotation

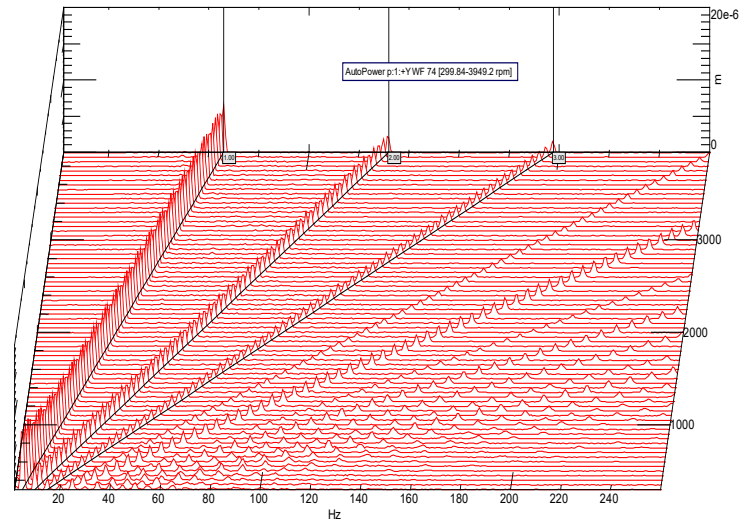

Fig. 7. Cascade plot for modified RK in configuration 2, cw rotation

Whirl inception in plain journal bearings depends on two independent non-dimensional parameters, i.e. the Sommerfeld number $S$ and the ratio between bearing axial length and diameter. The inverse of $\mathrm{S}$ is the nondimensional bearing load, so that the higher the Sommerfeld number, the lower the load and the threshold speed. Particularly, S is inversely proportional to the square of the clearance and, therefore, whirl inception is very sensitive to this parameter, i.e. the lower the clearance, the lower the threshold speed. Sommerfeld number and clearance are global bearing parameters that are sensible for accurately aligned bearings. Differently, when the shaft misalignment is considerable, whirl inception should be linked to local parameters, i.e. the local film thickness or the average clearance in the active film region (where the pressure distribution develops). Consequently, if the shaft is not misaligned, whirl threshold does not depend on rotation speed direction. Indeed, for opposite rotation speeds, the corresponding film thickness distributions are symmetric with respect to the vertical bearing mid-plane and the average clearance of the active film is the 
same. Differently, if the shaft is misaligned, the average thickness of the active film and consequently the threshold speed may depend on the rotation speed direction.

In order to illustrate the degree of agreement between experiments and simulations, Figures 8 and 9 show in percentage the differences between measured and computed relative eccentricities (ratio between journal eccentricity and hot radial clearance). For the assessment of such differences, referred to as errors, the simulation results of "2D adiabatic" and "2D correlation" models are used in Figs. 8 and 9, respectively. Both of these plots point out that the modified RK errors (red and green columns for configuration 1 and 2, respectively) are far lower than original RK ones (blue columns).

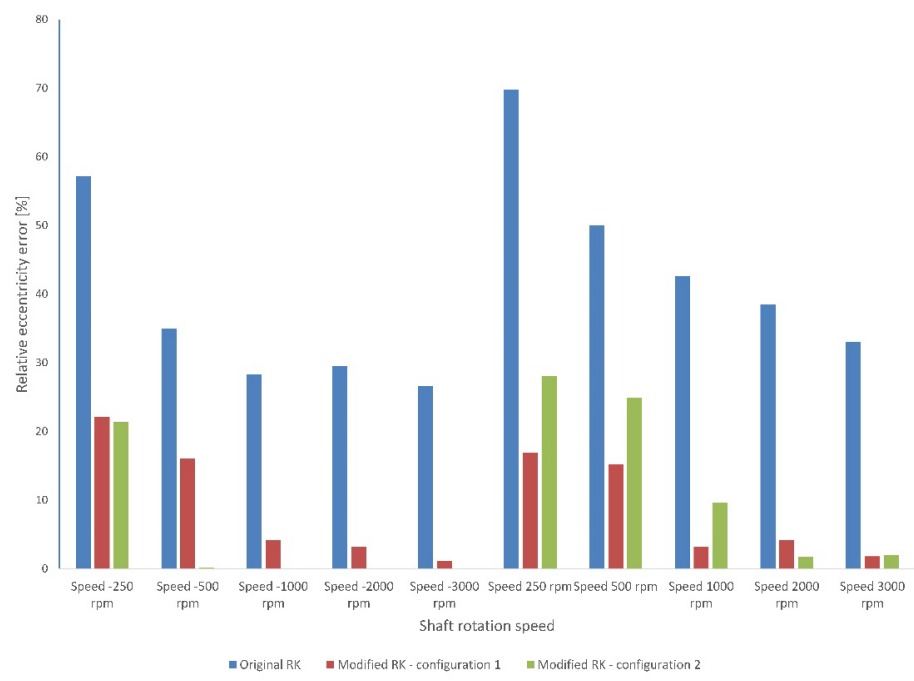

Fig. 8. Difference between measured and $2 \mathrm{D}$ adiabatic model relative eccentricities for different test rigs and configurations

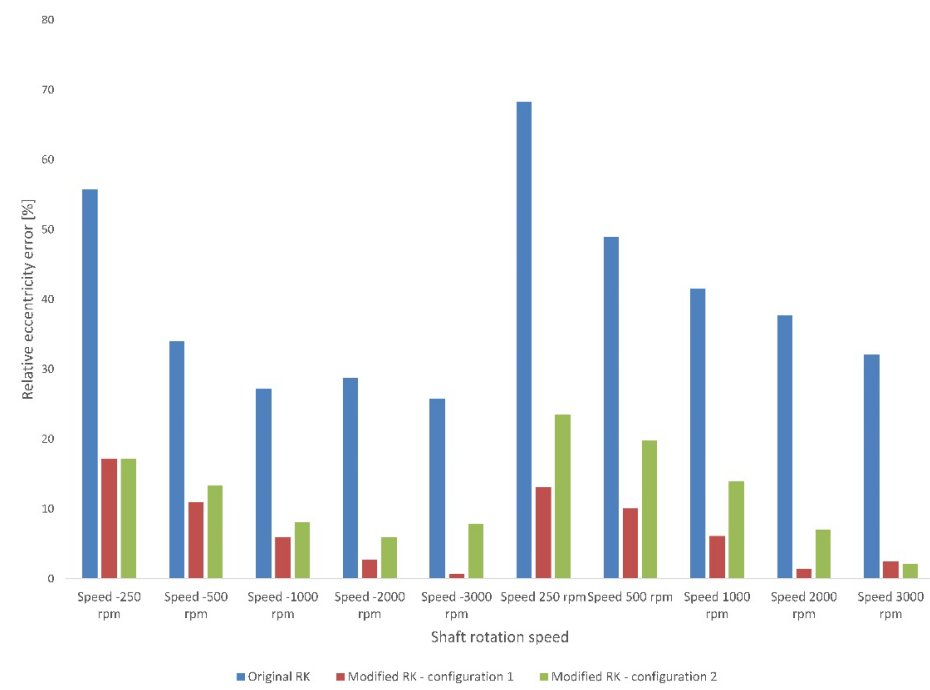

Fig. 9. Difference between measured and 2D correlation model relative eccentricities for different test rigs and configurations 
Although such reduction is less significant for the modified RK in configuration 2 (green columns) for ccw (positive) rotation speeds, the relevant measurements are not significant equilibrium locations due to the occurrence of whirl, as mentioned above. As far as the attitude angle error is concerned, the drop is more moderate. A full three-dimensional THD analysis or even a TermoElastoHydrodynamic (TEHD) analysis would be required in order to achieve close agreement of attitude angles.

\section{Conclusions}

A reduction in the clearance of the original RK has improved the correlation between experiments and real-world applications as well as the agreement with numerical results from codes implemented for lubrication analysis. In future research, the new test rig set up in this work will be employed for the dynamic analysis of bearing-rotor systems. Aerodynamic bearings for oil-free lubrication will be also studied.

This project has received funding from the European Union's Horizon 2020 research and innovation programme under grant agreement No 764706, Pump-Heat project

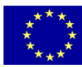
(https://www.pumpheat.eu/).

\section{References}

1. J. Tůma, J. Biloš, Fluid Induced Instability of Rotor Systems with Journal Bearings, Eng. Mechanics, 14, 1-2, 69-80 (2007)

2. V. Meruane, Identification of nonlinear dynamic coefficients in plain journal bearings, Trib. Int., 41, 8, 743-754 (2008)

3. J. Tůma, A. Bilošová, J. Šimek, R. Svoboda, A Simulation Study of the Rotor Vibration in a Journal Bearing, Eng. Mechanics, 15, 6, 461-470 (2008)

4. F. Stefani, A. Rebora, Steadily loaded journal bearings: Quasi-3D mass-energyconserving analysis, Trib. Int., 42, 3, 448-460 (2009)

5. F. Stefani, FEM Applied to Hydrodynamic Bearing Design, New Tribological Ways, 451-476 (2011)

6. B. Nevada, Rotor kit servofluid control bearing option manual, Nevada: Bently (2000).

7. M. Trachsel, R. Pittiti, and J. Dual, Friction and 2D position measurements in small journal bearings, Trib. Int., 6 (2016)

8. F. Stefani, Design and fast verification of pocket elliptical journal bearings, Ind. Lubr. and Trib., 66, 393-401 (2014)

9. B. Jacobsson, L. Floberg, The Finite Journal Bearing Considering Vaporization, Trans. of Chalmers University of Technology, 190 (1957)

10. K. Olsson, Cavitation in Dynamically Loaded Bearings, Trans. of Chalmers University of Technology, 308 (1965)

11. A. Kumar, J.F. Booker, A Mass and Energy Conserving Finite Element Lubrication Algorithm, ASME J. Tribol., 116, 4, 667-671 (1994)

12. C. Gazley, Heat-transfer characteristics of the rotational axial flow between concentric cylinders, Trans. of the ASME, 80, 79-90 (1958) 